\title{
Renal Failure in Mice with Gs $\alpha$ Deletion in Juxtaglomerular Cells
}

\author{
Limeng Chen ${ }^{a, b}$ Robert Faulhaber-Walter ${ }^{a, d}$ Yubing Wen ${ }^{b}$ Yuning Huang ${ }^{a}$ \\ Diane Mizel $^{\mathrm{a}}$ Min Chen $^{\mathrm{a}}$ Maria Luisa Sequeira Lopez ${ }^{\mathrm{c}}$ Lee S. Weinstein ${ }^{\mathrm{a}}$ \\ R. Ariel Gomez ${ }^{c}$ Josephine P. Briggs ${ }^{a}$ Jurgen Schnermann ${ }^{a}$ \\ ${ }^{a}$ National Institute of Diabetes and Digestive and Kidney Diseases, NIH, Bethesda, Md., USA; \\ ${ }^{b}$ Chinese Academy of Medical Science and Peking Union Medical College Hospital, Beijing, China; \\ 'University of Virginia, Charlottesville, Va., USA; ${ }^{\mathrm{d} M e d i c a l ~ S c h o o l ~ H a n n o v e r, ~ H a n n o v e r, ~ G e r m a n y ~}$
}

\section{Key Words}

Renin-angiotensin system $\cdot$ Renal failure $\cdot$ Pathology

\begin{abstract}
Background: Mice with deletion of Gs $\alpha$ in renin-producing cells (RC/FF mice) have been shown to have greatly reduced renin production and lack of responsiveness of renin secretion to acute stimuli. In addition, young RC/FF mice are hypotensive and have a vasopressin-resistant concentrating defect. In the present study we have determined the longterm effect on renal function, blood pressure, and renal pathology in this low renin and diuretic mouse model. Methods and Results: Urine osmolarity of RC/FF mice was decreased in all age groups. GFR measured at 7, 14 and 20 weeks of age declined progressively. Single nephron GFR similarly declined while fractional proximal fluid absorption was maintained. Expression levels of extracellular matrix proteins (collagen I, IV and fibronectin) and $\alpha$-smooth muscle actin were increased in kidneys of RC/FF mice at 20 weeks, and this was accompanied by focal segmental glomerulosclerosis and periglomerular interstitial fibrosis. RC/FF mice showed a progressive reduction of body weight, an increase in urine albumin excretion, and an increase of blood pressure with aging. Conclusion: A chronic reduction of renin
\end{abstract}

\section{KARGER}

(C) 2010 S. Karger AG, Basel

Fax +4161306 1234 E-Mail karger@karger.ch www.karger.com www.karger.com/ajn production in mice may be a risk factor in its own right, and does not protect renal function against the profibrotic influence of a chronically elevated urine flow.

Copyright $\odot 2010$ S. Karger AG, Basel

\section{Introduction}

Blockade of the effects of angiotensin II by inhibition of renin, angiotensin-converting enzyme (ACE), or angiotensin II receptors (AT1) is a major protective intervention against renal injury of various origins. Reducing the impact of angiotensin II effects has been found beneficial in diabetic nephropathy, hypertension, and in urinary tract obstruction models of renal disease [1-3]. Conversely, transgenic rats with overexpression of renin are hypertensive and develop renal disease with albuminuria and hypertensive nephropathy [4]. Similarly, mice with overexpression of angiotensinogen only in the kidney also develop high blood pressure (BP), albuminuria and renal injury [5]. On the other hand, complete 'knockout' of components of the renin-angiotensin system (RAS) in mice produces a syndrome of early postnatal developmental pathology characterized by papillary hypotrophy and concentrating defect, renal vascular hypertrophy, fi- 
brosis and inflammation, and salt depletion and arterial hypotension [6-11]. Thus, the consequences of a persistently large reduction of renin secretion on renal structure and function are not entirely predictable. Mice with conditional deletion of the renin-stimulatory $\mathrm{Gs} \alpha$ protein in juxtaglomerular cells (RC/FF mice) have been shown to have a marked and chronic reduction, but not complete inhibition of renin production and secretion, and they are virtually unable to adequately augment renin secretion in response to physiological signals [1].

The goal of the present study was to examine age-dependent changes in renal function and renal histopathology in the low renin RC/FF model. In contrast to the RAAS knockout mice, all components of this system are structurally intact so that one might expect a lower level of overall RAAS dysfunction. On the other hand, the low renin status of these mice may be complicated in the intact animal by confounding factors. For example, RC/FF mice have a chronically elevated urine flow which is associated with the development of pelvic space dilation and papillary effacement. Hydronephrosis, usually generated by ureteral obstruction, provides a strong profibrotic and proinflammatory environment $[12,13]$, so that it was unclear whether the low renin state would be able to provide effective renal tissue protection. Despite the low renin expression and secretion and the low $\mathrm{BP}$ at a young age, our data show that RC/FF mice develop severe interstitial fibrosis and a steep decline in renal function with aging.

\section{Methods}

\section{Animals}

Mice with tissue-specific deletion of Gs $\alpha$ in renin-producing cells were generated from crosses of mice in which the endogenous renin promoter was used to control the expression of Cre recombinase in juxtaglomerular cells and mice in which exon 1 of the Gs $\alpha$ gene was flanked by LoxP sites [1]. Mice were derived from colonies of both strains maintained at the NIH. Animal care and experimentation were approved by the NIDDK Animal Care and Use Committee and carried out in accordance with National Institutes of Health principles as outlined in their Guide for the Care and Use of Laboratory Animals. Mice were genotyped as described previously [1].

\section{GFR in Conscious Mice}

GFR of conscious mice was measured by FITC inulin clearance after a single retroorbital injection and consecutive blood sampling from the tail vein $[14,15]$.

\section{Micropuncture}

To determine nephron filtration and reabsorption rates, micropuncture was done as described before [16].
$B P$ and Heart Rate

$\mathrm{BP}$ and heart rate of $\mathrm{WT}$ and $\mathrm{RC} / \mathrm{FF}$ mice were measured by a programmable sphygmomanometer using the tail-cuff method as described previously [17].

\section{Plasma Volume}

Plasma volume of conscious mice was measured as the distribution volume of injected Evans blue [15]. During a short isoflurane anesthesia, $30 \mu \mathrm{l}$ of a $5-\mathrm{mg} / \mathrm{ml}$ Evans blue solution was injected retroorbitally, and blood collections of approximately $5 \mu \mathrm{l}$ were made by tail-vein puncture at 7 and $15 \mathrm{~min}$. Absorbance at $620 \mathrm{~nm}$ was measured in a 1:5 dilution of plasma in a ND-1,000 Nanodrop spectrophotometer and compared with a standard curve.

RT-PCR

Total kidney RNA was extracted (RNeasy Mini Kit; Qiagen, Valencia, Calif., USA) and treated with DNase I (Invitrogen, Carlsbad, Calif., USA) at room temperature for $15 \mathrm{~min}$. Reverse transcription was performed using SuperScript II (SuperScript II first-strand synthesis system for RT-PCR; Invitrogen). Collagen IV mRNAs were detected by real-time PCR (ABI PRISM ${ }^{\circledR} 7900 \mathrm{HT}$ Sequence Detection System; ABI, USA) using primers and probes from Applied Biosystems. $\beta$-Actin cDNA (primers and probe obtained from Applied Biosystems) or 18s rRNA were used as housekeeping control [1].

Immunoblotting

Renal cortical and medullary tissue was dissected in ice-cold buffer. Western blotting was performed according to standard protocols using a polyclonal anti- $\alpha$-smooth muscle actin ( $\alpha$-SMA) antibody. Coomassie blue-stained gels served as loading controls [1].

\section{Urine Collection}

Twenty-four-hour urine collections were made in metabolic cages at ambient room temperature with unrestricted access to tap water and standard rodent diet. Urine albumin was determined by ELISA (Albuwell M; Exocell, Inc., Philadelphia, Pa., USA). Urine osmolarities were determined in spot urine samples.

\section{Histology}

Standard staining and immunoperoxidase techniques were used as previously described [15]. 3- $\mu \mathrm{m}$ sections were cut from paraffin-embedded tissue and stained with periodic acid-Schiff, hematoxylin and eosin, and Masson trichrome for light microscopy or restained for immunohistochemistry. Immunohistochemistry was performed using the following affinity-purified primary antibodies: goat polyclonal antibody against collagen (Col) I and Col IV (SouthernBiotech, Birmingham, Ala., USA), Rabbit polyclonal antibody against $\alpha$-SMA (Abcam, Inc., Cambridge, Mass., USA), against caspase-3 (BD Pharmingen, Franklin Lakes, N.J., USA). Secondary antibodies were goat anti-rabbit IgG and rabbit anti-goat IgG (Rockland, and the Vectastain Elite ABC Kit from Vector Laboratories, Inc., Burlingame, Calif., USA). Immunohistochemical stains were quantified using a computer-based morphometric analysis software (Beihang Pathology Analysis System, Beijing, China), that allowed the formation of a binary image in which the stained area could be automatically calculated as percentage of the image area. Ten fields per specimen were randomly selected that covered nearly the whole piece of cortex. Scoring was performed blind on coded slides [18]. 
Glomerular Injury Score

The Glomerular Injury Score was determined by examining all glomerular profiles contained within one or two coronal sections from each kidney and expressed as the percentage of the total number of glomeruli counted. A minimum of 80 glomeruli per kidney was evaluated for glomerulosclerosis. Each glomerulus was graded as follows: grade $0=$ normal glomerulus by light microscopy; grade 1 = involvement of up to one-third of the glomerular area; grade 2 = involvement of one- to two-thirds of the glomerulus, and grade 3 = two-thirds to global sclerosis. Each score was then calculated according to the formula: Glomerular Injury Score $=[(1 \times$ number of grade 1 glomeruli $)+(2 \times$ number of grade 2 glomeruli $)+(3 \times$ number of grade 3 glomeruli $)] \times 100 /$ (number of glomeruli observed)] [19].

\section{Statistics}

Unpaired t test was used to compare two values between different animals. $\mathrm{p}<0.05$ was considered significant.

\section{Results}

\section{Renal Function}

GFR measured by FITC insulin elimination kinetics in conscious mice at 7 weeks of age was lower in $\mathrm{RC} / \mathrm{FF}$ than WT animals. GFR decreased further at 14 and 20 weeks of age whereas no such change was seen in WT

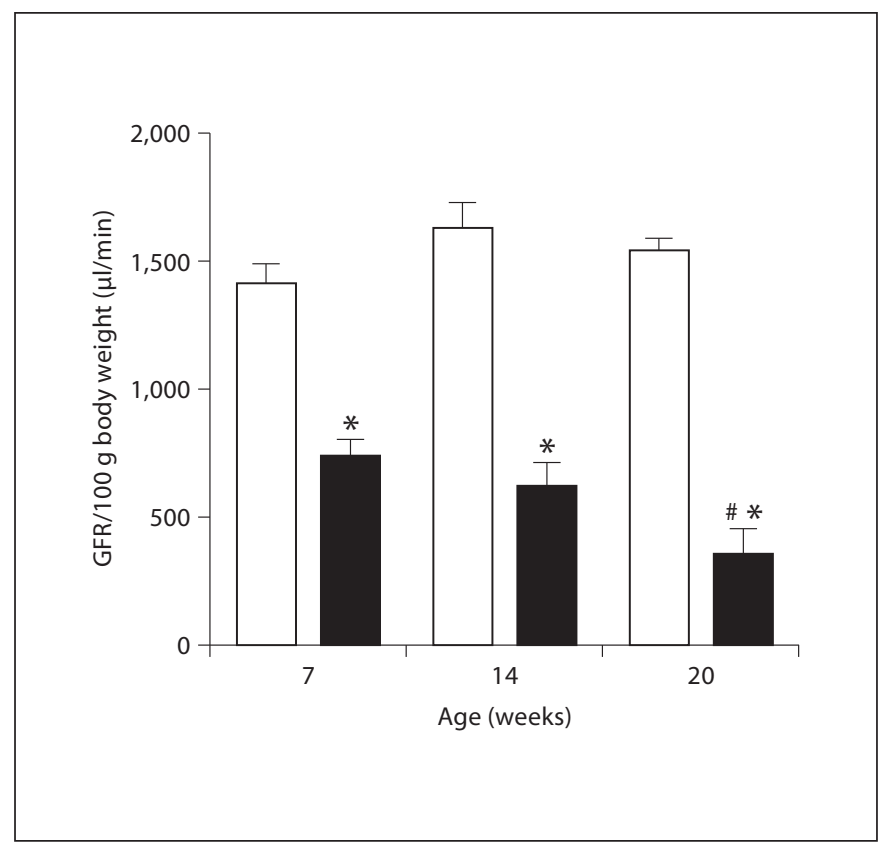

Fig. 1. GFR in conscious WT ( $\square$ ) and RC/FF ( $\square$ ) mice at the ages of 7,14 and 20 weeks. Significances are given for comparisons with GFR of WT mice of the same age $\left({ }^{*} \mathrm{p}<0.0001\right)$ and for comparisons with GFR of RC/FF mice at the age of 7 weeks ( ${ }^{\#} \mathrm{p}=$ 0.0095).
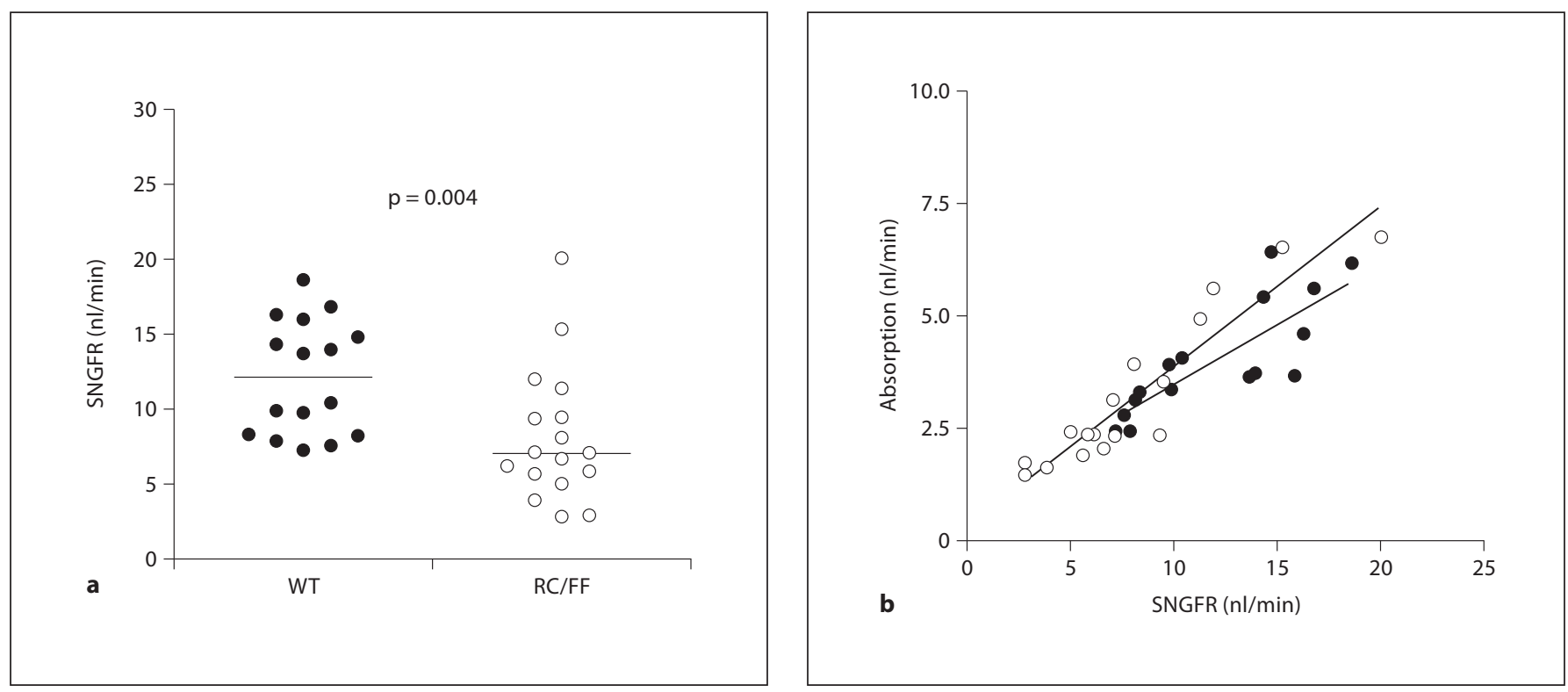

Fig. 2. a SNGFR in anesthetized RC/FF and WT mice in the 16- to 20-week age range. $\mathbf{b}$ Relationship between SNGFR and proximal tubular fluid reabsorption in RC/FF $(\bigcirc)$ and WT $(\bullet)$ mice. 


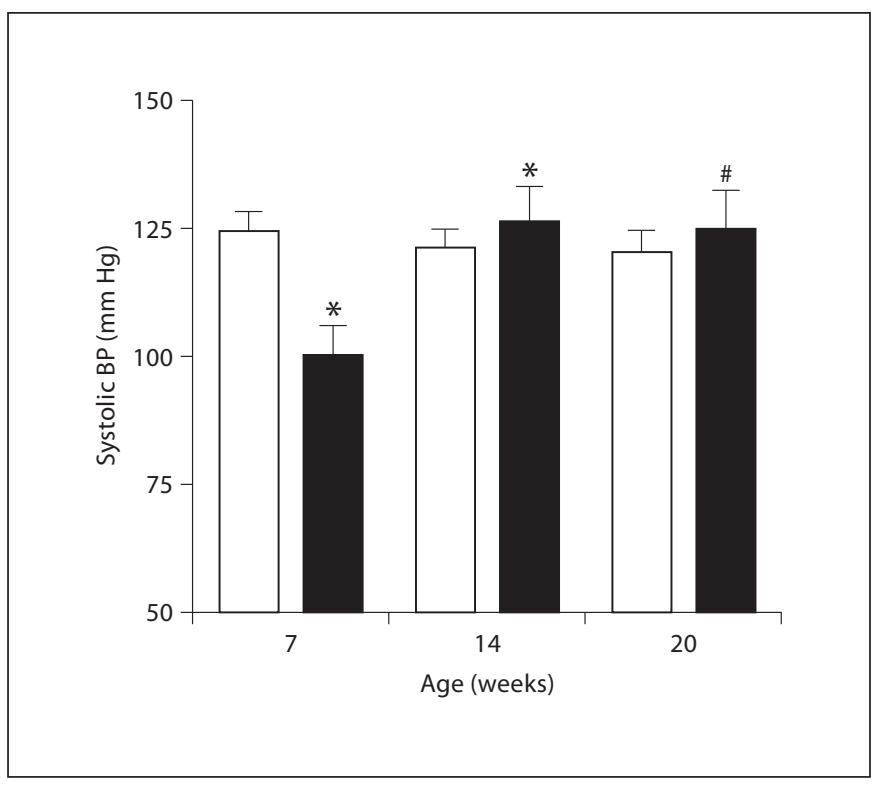

Fig. 3. Systolic BP measured by tail-cuff inflation method in WT $(\square)$ and RC/FF ( $\square$ ) mice at 7, 14, and 20 weeks of age. Significances are given for comparison with $\mathrm{BP}$ of WT mice at the same age $\left({ }^{*} \mathrm{p}<0.01\right)$ and with mice of the same genotype at age 14 weeks ${ }^{*} \mathrm{p}<0.01$, unpaired $\mathrm{t}$ test $)$ and 20 weeks $\left({ }^{\#} \mathrm{p}<0.05\right.$, unpaired $\mathrm{t}$ test).

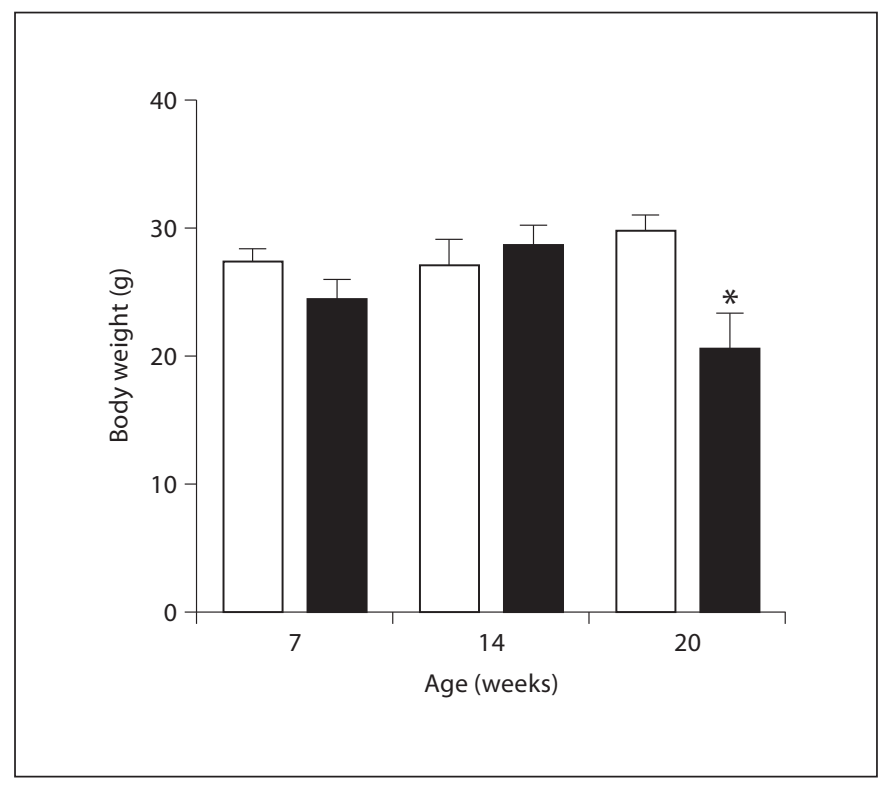

Fig. 4. Decrease of body weight in RC/FF mice ( $\boldsymbol{\square}$ ) at 20 weeks; significance given for comparison with the body weight of WT mice $(\square)$ at the same age ( $\mathrm{p}=0.0026$, unpaired t test).

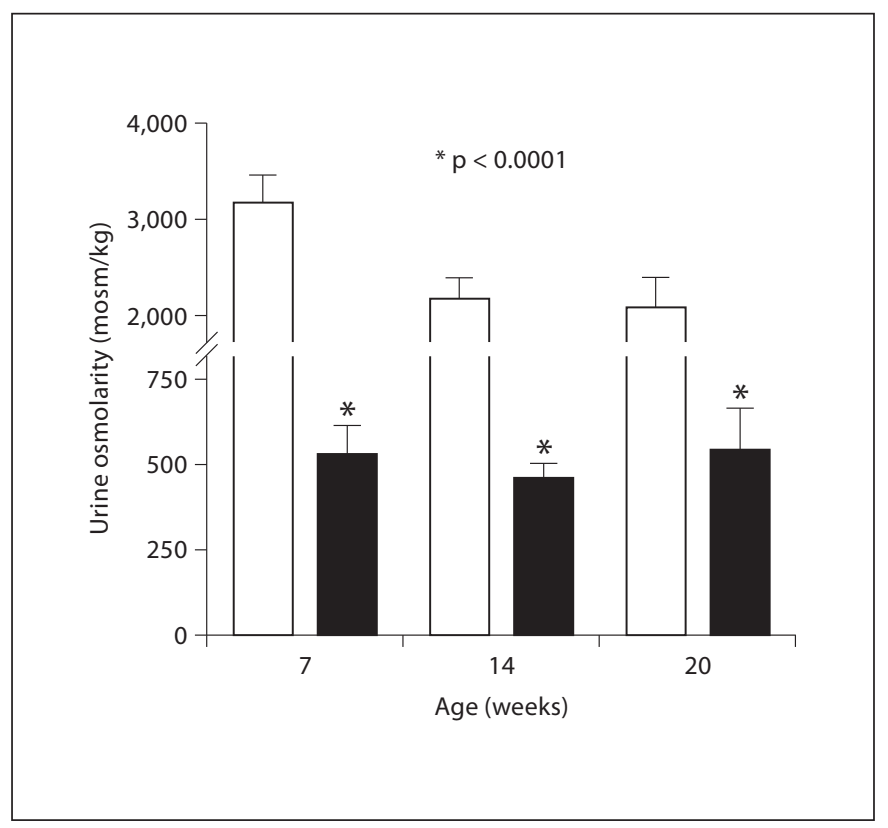

Fig. 5. Urine osmolarity of WT ( $\square$ ) and RC/FF ( $\square$ ) mice at different ages; significance given for comparisons with urine osmolarity of WT mice at the same age $(\mathrm{p}<0.0001$, unpaired $\mathrm{t}$ test). animals (fig. 1). Micropuncture measurements of single nephron GFR (SNGFR) performed in the 16- to 20 -week age groups range confirmed the reduction of GFR and in addition demonstrated a considerably higher level of SNGFR heterogeneity in the RC/FF animals (fig. 2). BP in the group of RC/FF mice used for micropuncture was significantly higher than WT $(119 \pm 4$ vs. $95 \pm 2 \mathrm{~mm} \mathrm{Hg}$; $\mathrm{p}<0.001$ ), a difference that may reflect the effect of age or differing responses to the anesthesia. Since SNGFR measured by proximal fluid collections is pressure-dependent, it is likely that the SNGFR difference between genotypes is underestimated. Proximal fluid absorption was reduced in absolute terms, but there was no change of fractional reabsorption suggesting that absorption was appropriate for the reduced GFR.

\section{Blood Pressure}

Previous telemetric measurements of BP had shown lower values in RC/FF mice [1], and this was confirmed in the present study by tail-cuff plethysmography (fig. 3). However, BP in RC/FF mice increased in older mice reaching values that were not different from $\mathrm{WT}$ at 14 and 20 weeks. 
Fig. 6. A a Cross section of a kidney of a RC/FF (left) and WT mouse (right). Note hydronephrosis with atrophic papilla in the RC/FF kidney. b-d Kidney cortex of 20-week-old RC/FF (c, d) and WT mice (b) stained with Masson trichrome (d) or PAS (b, c). $200 \times$. Note focal segmental glomerulosclerosis and periglomerular interstitial fibrosis in RC/FF mice (c, d). e Glomerular injury score in RC/FF ( $\boldsymbol{\square})$ and $\mathrm{WT}(\square)$ mice.
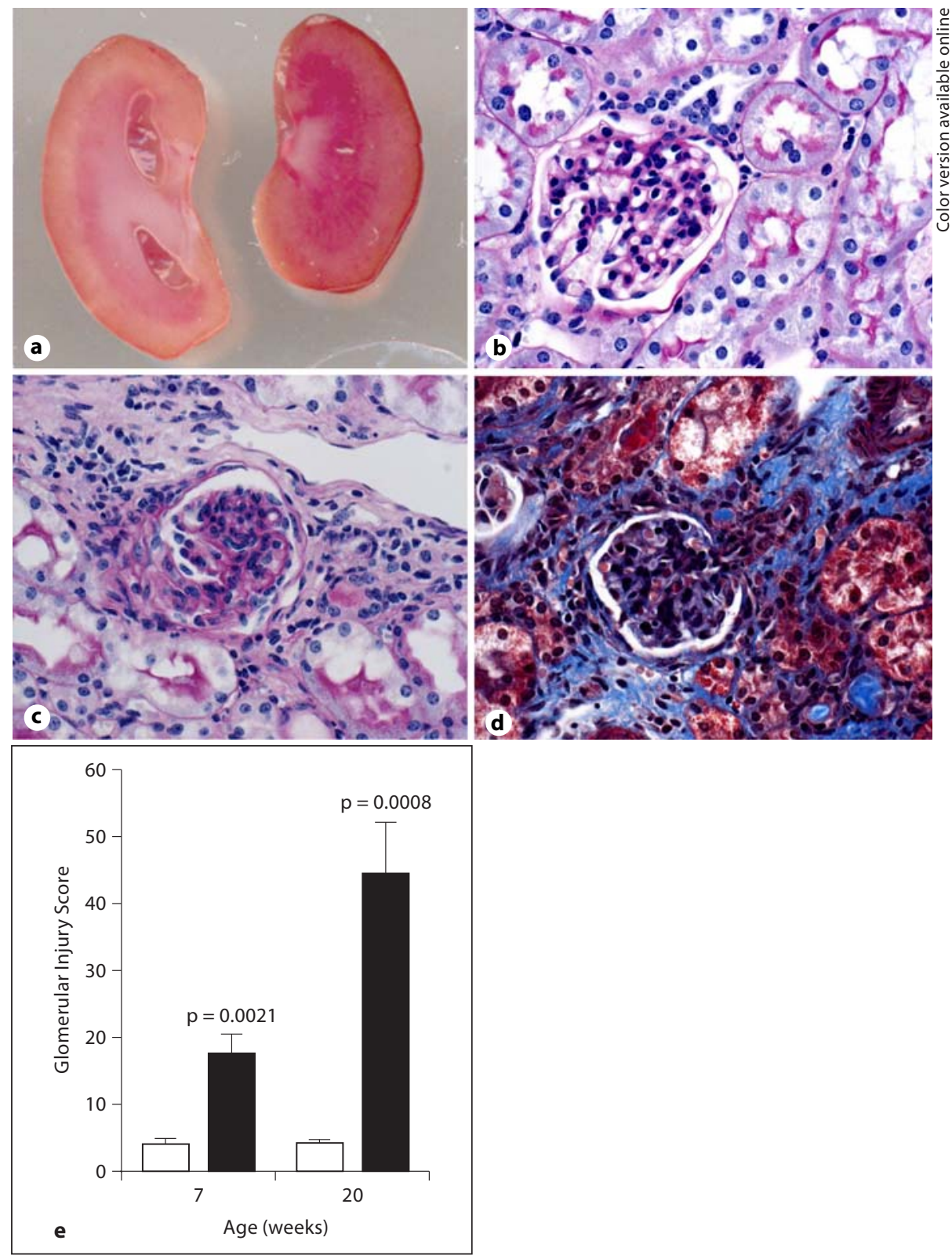

\section{Plasma Volume and Body Weight}

Plasma volume was significantly lower in $\mathrm{RC} / \mathrm{FF}$ than in WT mice $(4.6 \pm 0.5$ vs. $6.5 \pm 0.5 \%$ of body weight; $\mathrm{p}=0.042$ ) at 7 weeks of age. At 20 weeks of age there was also a measurable reduction of body weight in the RC/FF mice (fig. 4).

\section{Urine Osmolarity}

Ambient urine osmolarity (fig. 5) of RC/FF mice was on average about $25 \%$ lower than that of WT mice, and this difference was not affected by age.
Fibrosis Markers and Urinary Albumin Excretion

$\mathrm{RC} / \mathrm{FF}$ mice demonstrated major morphological changes in the kidney at 20 weeks of age (fig. 6A), but not at 6 weeks of age (fig. 6B). As a result of the chronically increased urine flow, there was probably a marked dilation of the renal pelvis and atrophy of the renal parenchyma from the inner medulla to the outer stripe (fig. 6Aa). There was histological evidence for focal segmental glomerular sclerosis and periglomerular interstitial fibrosis (fig. 6Ac, Ad). Staining with Masson trichrome (fig. 6Ad) and periodic acid-Schiff (fig. 6Ac) was 
Fig. 6. B Kidney cortex of 6-week-old RC/ FF (b, d, f) and WT mice (a, c, e) stained with HE (a, b), PAS (c, d) or Masson trichrome (e, f). $200 \times$.
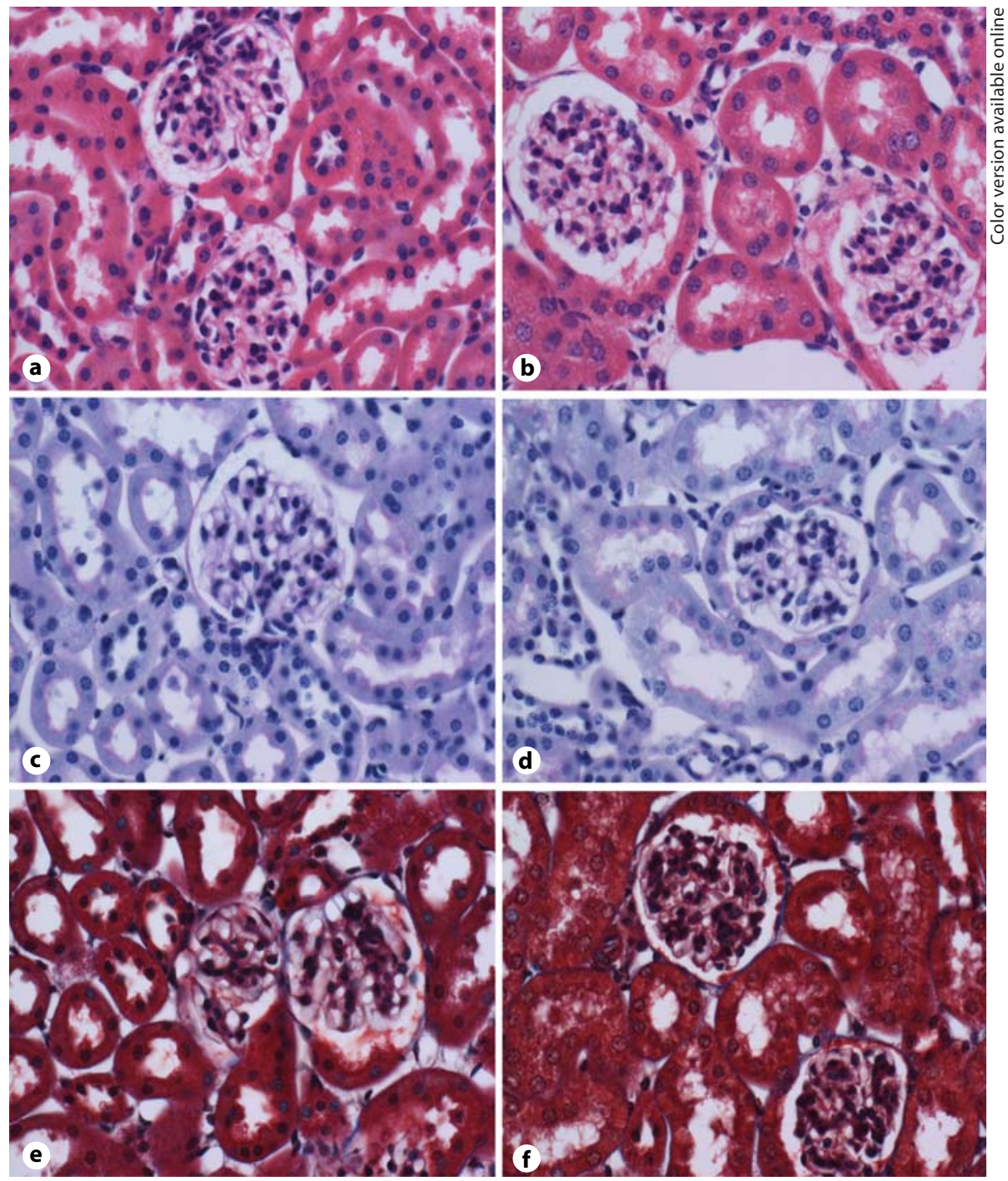

more pronounced in the $\mathrm{RC} / \mathrm{FF}$ mice at 20 weeks of age. The glomerular injury index was 4 times higher at 7 weeks $(\mathrm{p}=0.0044)$ and 10 times higher at 20 weeks $(\mathrm{p}=$ 0.0022) compared with WT mice of the same age (fig. 6Ae). Albumin excretion of RC/FF mice was significantly elevated compared to WT mice $(81.4 \pm 17.9$ vs. $34.2 \pm 4.9$ $\mu \mathrm{g} /$ day; $\mathrm{p}=0.017, \mathrm{n}=14$ ) with matched ages ( 7 weeks $\mathrm{n}=$ 5,14 weeks $n=5,20$ weeks $n=4$ ).

Immunohistochemistry demonstrated expression of collagen I and collagen IV in the fibrotic areas (fig. 7-9). An increase in collagen IV mRNA was also observed in RNA extracts from the kidney cortex (fig. 9d).

Preglomerular arteriolar vessels were thickened and the increase in media wall thickness was associated with dramatic increases in $\alpha$-SMA expression (fig. 10). In addition, $\mathrm{RC} / \mathrm{FF}$ mice displayed an increase in $\alpha$ SMA-positive cells in glomeruli (reflecting activated mesangial cells) and in areas of periglomerular and interstitial fibrosis presumably representing myofibroblasts (fig. 10, 11).

\section{Apoptosis and Caspase-3}

Evidence of apoptosis was observed in RC/FF mice by TUNEL staining, and this was accompanied by increased levels of caspase-3. Caspase-3 was mainly located in damaged tubules, but was also found in some glomerular and interstitial cells (fig. 12). 
Fig. 7. Expression of collagen I in the kidney of WT and RC/FF mice at age 7 weeks (a, b) and 20 weeks (c, d). a, c Immunohistochemical staining for collagen I in WT mice. b, d Immunohistochemical staining for collagen I in RC/FF mice. $200 \times$. e Quantification by morphometric analysis (20 weeks).
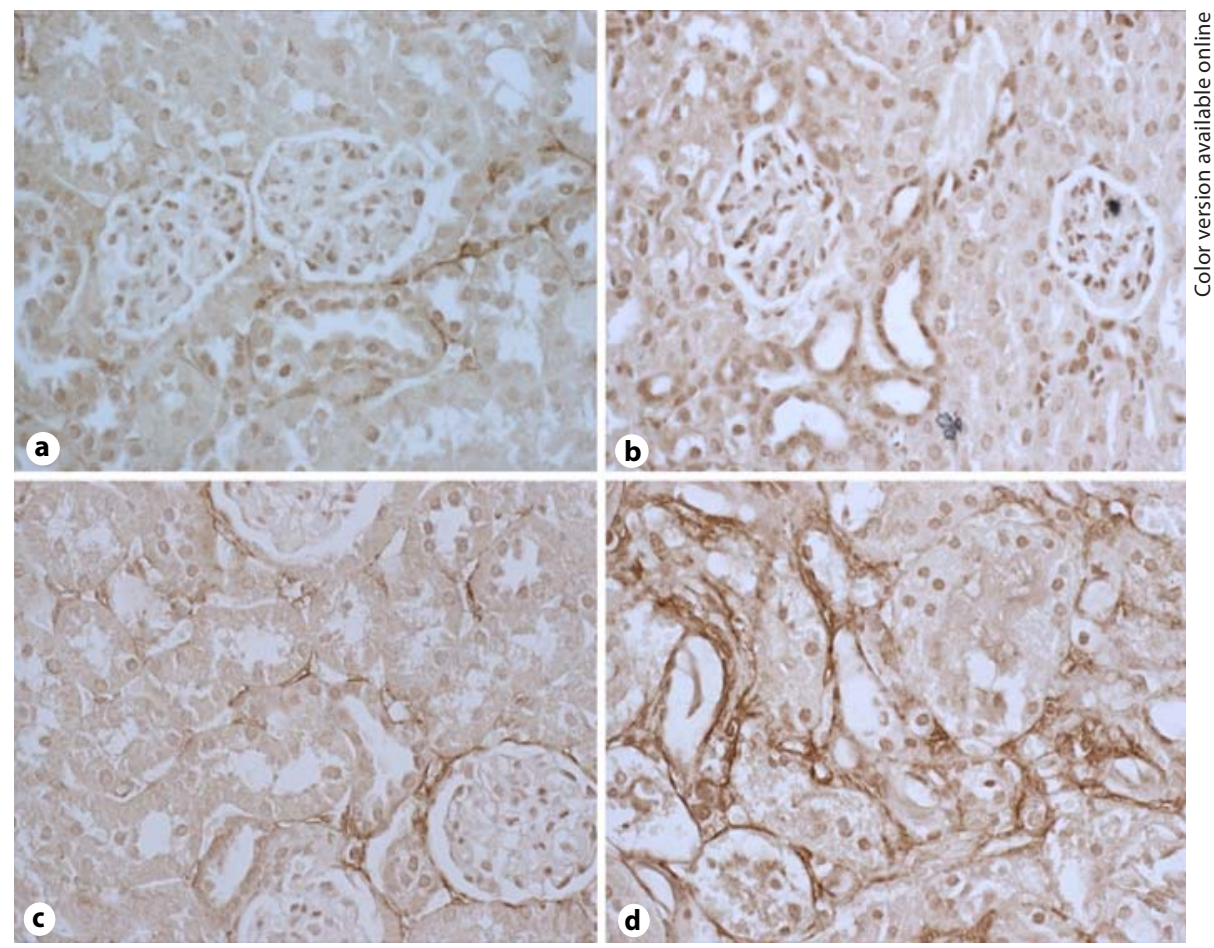

\section{Discussion}

The present experiments were performed as a longitudinal examination of renal structure and function in a mouse model that was found to have very low levels of renin expression. The rationale behind these studies is an uncertainty about the role of suppressing the RAS in the protection of renal integrity. On the one hand, inhibition of the RAS by ACE or angiotensin receptor blockers is currently the main proven intervention aimed to prevent the onset of chronic nephropathies and their progression to end-stage renal disease [20]. On the other hand, homozygous mice with targeted deletions of the genes encoding angiotensinogen (Agt-/-) or ACE (Ace-/-) show an early postnatal development of renal histological abnormalities that are strikingly similar, and consist of papillary atrophy and a concentrating defect as well as structural abnormalities such as wall thickening of intrarenal arterioles. These results seem to indicate that an extreme degree of angiotensin deficiency has negative conse- 
Fig. 8. Expression of fibronectin in the kidney of WT and RC/FF mice at 7 weeks (a, b) and age 20 weeks (c, d). a, c Immunohistochemical staining for fibronectin in WT mice. b, d Immunohistochemical staining for fibronectin in RC/FF mice. $200 \times$. e Quantification by morphometric analysis (20 weeks).
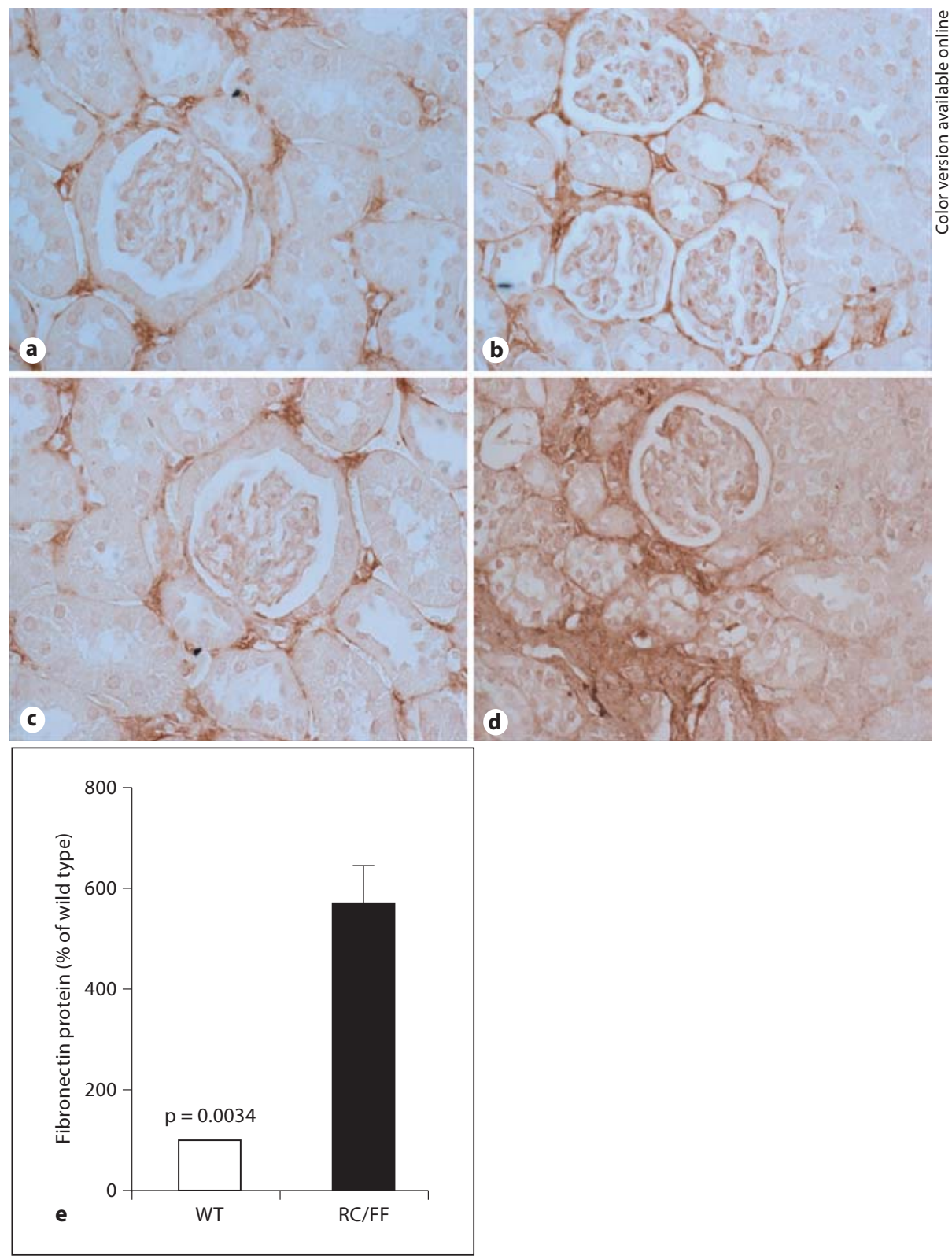

quences for the maintenance of a normal renal structure during development [21].

The present data show that the marked suppression of the RAS in mice lacking Gs $\alpha$-dependent signaling in juxtaglomerular cells is associated with growth retardation, a reduced GFR and albuminuria. Specifically, low renin $\mathrm{RC} / \mathrm{FF}$ mice develop premature vascular disease that was associated with an increase in $\alpha$-SMA-positive cells indicating myofibroblastic transdifferentiation and with a marked expansion of the arteriolar media, and destruction of endothelial cells. The age-related decline of GFR was accompanied by focal segmental glomerular sclerosis and periglomerular and focal interstitial fibrosis.

Furthermore, RC/FF mice show a marked increase in the expression of vasoactive, profibrotic, and immune mediators [22] with increased deposition of matrix molecules (collagen I, collagen IV, fibronectin) associated with focal areas of fibrosis. In addition, apoptosis of tubular cells and increased expression of caspase-3 were also observed. An involvement of apoptosis and caspase-3 in mediating long-term ischemia/reperfusion and immunosuppressive injury have been previously reported [23]. 
Fig. 9. Expression of collagen IV in the kidney of WT and RC/FF mice at 7 weeks (a, b) and age 20 weeks (c, d). a, c Immunohistochemical staining for collagen IV in WT mice. b, d Immunohistochemical staining for collagen IV in RC/FF mice. $100 \times$. e Quantification by morphometric analysis (20 weeks). f Collagen IV mRNA expression determined by real-time PCR.
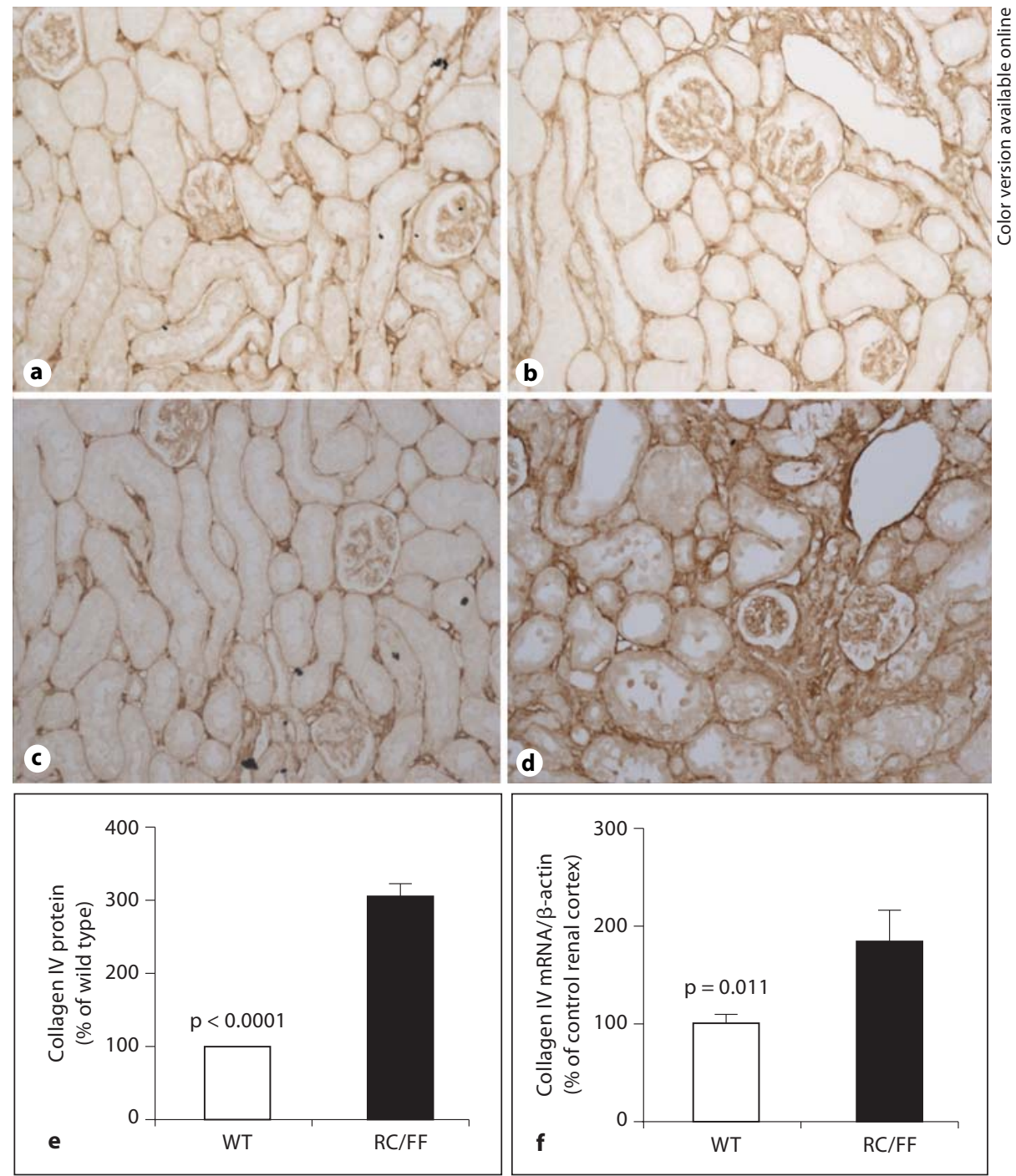

While the overall renal pathology in $\mathrm{RC} / \mathrm{FF}$ mice resembles the phenotype observed in AT1A/AT1B double knockout mice [6,21], it is to be noted that the onset of the structural alterations is much slower. Mice with complete knockout of one of the components of the RAS develop abnormalities within the first 3 postnatal weeks [24], whereas kidney structure and function is largely normal in $\mathrm{RC} / \mathrm{FF}$ mice at 8 weeks of age. It is conceivable that this difference is a reflection of a total versus a partial interference with the RAS. In that regard, it is noteworthy that deletion of AT1A receptors causes rapid renal structural alterations only when AT1B receptors are also removed.

Although downregulation of the RAS may be causal in the structural abnormalities of RC/FF mice, renin-independent consequences of Gs $\alpha$ deletion must also be consid- ered. As has been observed earlier, RC/FF mice have a marked decrease of urine osmolality resulting from an unexpected reduction of medullary Gs $\alpha$ signaling that interfered with vasopressin action. The concentrating defect was associated with dilated renal pelvis and atrophied renal papillary parenchyma. Although we did not determine renal pelvic pressures it is conceivable that hydronephrosis contributed to the structural alterations seen in $\mathrm{RC} / \mathrm{FF}$ mice. It is well established that overt hydronephrosis as caused by complete or partial ureteral obstruction induces interstitial fibrotic and inflammatory responses [25]. Whether a high urine flow without obstruction is sufficient to induce tubulointerstitial fibrosis is not certain, but remains a possibility. Nevertheless, it is apparent that a low RAS does not seem to be protective under these conditions. 
Fig. 10. Expression of $\alpha$-SMA in kidneys of $\mathrm{WT}(\mathbf{a}, \mathbf{c}, \mathbf{e})$ and RC/FF mice $(\mathbf{b}, \mathbf{d}, \mathbf{f})$. Note increased expression of $\alpha$-SMA in blood vessels, and interstitial cells (representing myofibroblasts), and thicker arteries and arterioles in RC/FF mice (f); $\alpha$-SMA-positive cells are also present in mesangial areas (upper arrow in $\mathbf{f}$ ) and in periglomerular and interstitial areas (arrows in $\mathbf{b}$ and d). $400 \times$.

Fig. 11. Western blot quantification of $\alpha-$ SMA in the kidney cortex of WT and RC/ FF mice. a Immunoblot of $\alpha$-SMA in $3 \mathrm{RC} /$ FF (left) and 3 WT (right) at age 20 weeks with Coomassie blue staining for total protein as loading control (bottom). $\mathbf{b} \alpha$-SMA protein expression in $\mathrm{WT}(\square)$ and RC/FF ( ) mice determined by Western blotting $\left({ }^{*} \mathrm{p}<0.01, \mathrm{n}=9\right)$.
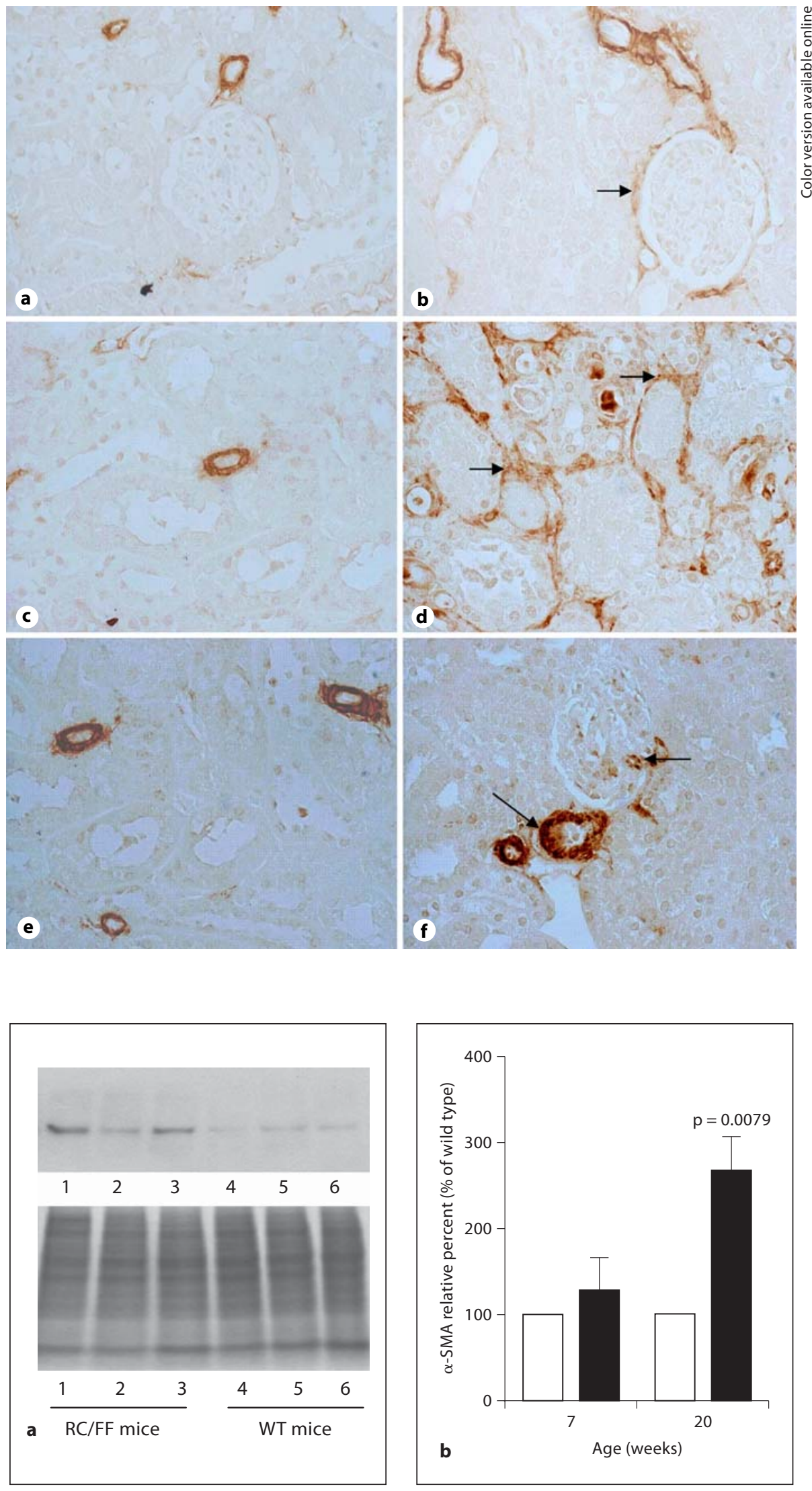

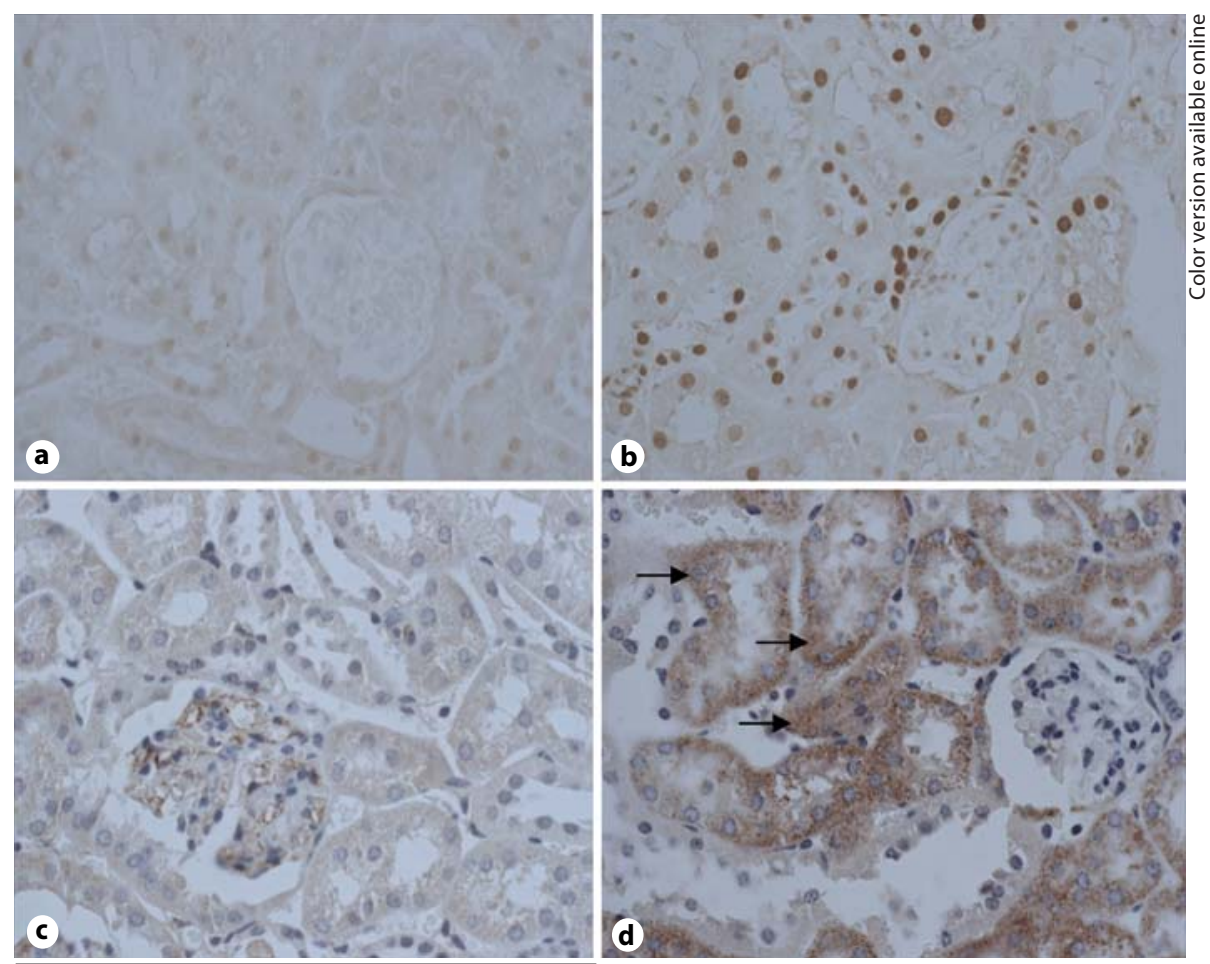

Fig. 12. a-d Evidence for apoptosis in kidneys of WT $(\mathbf{a}, \mathbf{c})$ and RC/FF mice $(\mathbf{b}, \mathbf{d})$ from TUNEL staining at 7 weeks of age (a, b, $200 \times$ ), immunohistochemical expression of caspase-3 (c, d, $400 \times)$. e Quantification of immunohistochemical expression of caspase- 3 in WT and RC/FF mice.

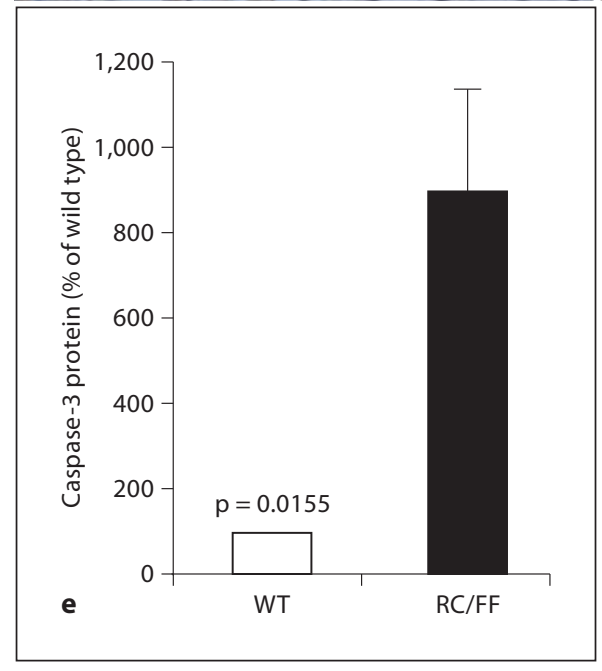

In summary, the present study showed that a low renin content and absence of regulated renin secretion in $\mathrm{RC} /$ FF mice is associated with progressive focal segmental glomerular sclerosis and periglomerular and focal interstitial fibrosis, and a decrease of kidney and SNGFR. Our data are in agreement with other studies suggesting that the renal protection afforded by inhibition of the RAS may not extend linearly throughout declining angiotensin levels and that renin-independent mechanisms exist for progressive renal impairment.

\section{Acknowledgements}

This work was supported by intramural funds from the National Institute of Diabetes and Digestive and Kidney Diseases, and by NIH grant HL 66242 (R.A.G.), the National Natural Science Foundation of China (No. 30770861, 30971369), and Scientific Research Foundation for Excellent Returned Scholars, Ministry of Human Resources of China. 


\section{References}

1 Chen L, Kim SM, Oppermann M, et al: Regulation of renin in mice with Cre recombinase-mediated deletion of $\mathrm{G}$ protein $\mathrm{Gs} \alpha$ in juxtaglomerular cells. Am J Physiol Renal Physiol 2007;292:F27-F37.

$\checkmark 2$ Maschio G, Alberti D, Locatelli F, et al: Angiotensin-converting enzyme inhibitors and kidney protection: the AIPRI trial. The ACE Inhibition in Progressive Renal Insufficiency (AIPRI) Study Group. J Cardiovasc Pharmacol 1999;33(suppl 1):S16-S20, S41-S43.

3 Klahr S: Urinary tract obstruction. Semin Nephrol 2001;21:133-145.

$\checkmark 4$ Mervaala EM, Muller DN, Park JK, et al: Monocyte infiltration and adhesion molecules in a rat model of high human renin hypertension. Hypertension 1999;33:389-395.

5 Yang G, Merrill DC, Thompson MW, Robillard JE, Sigmund CD: Functional expression of the human angiotensinogen gene in transgenic mice. J Biol Chem 1994;269:3249732502 .

6 Benndorf RA, Krebs C, Hirsch-Hoffmann B, et al: Angiotensin II type 2 receptor deficiency aggravates renal injury and reduces survival in chronic kidney disease in mice. Kidney Int 2009;75:1039-1049.

7 Oliverio MI, Kim HS, Ito M, et al: Reduced growth, abnormal kidney structure, and type 2 (AT2) angiotensin receptor-mediated blood pressure regulation in mice lacking both AT1A and AT1B receptors for angiotensin II. Proc Natl Acad Sci USA 1998;95: 15496-15501.

8 Yanai K, Saito T, Kakinuma Y, et al: Renindependent cardiovascular functions and renin-independent blood-brain barrier functions revealed by renin-deficient mice. J Biol Chem 2000;275:5-8.

$\checkmark 9$ Nagata M, Tanimoto K, Fukamizu A, et al: Nephrogenesis and renovascular development in angiotensinogen-deficient mice. Lab Invest 1996;75:745-753.
10 Kihara M, Umemura S, Sumida Y, et al: Genetic deficiency of angiotensinogen produces an impaired urine concentrating ability in mice. Kidney Int 1998;53:548-555.

11 Hilgers KF, Reddi V, Krege JH, Smithies O, Gomez RA: Aberrant renal vascular morphology and renin expression in mutant mice lacking angiotensin-converting enzyme. Hypertension 1997;29:216-221.

12 Oda T, Jung YO, Kim HS, et al: PAI-1 deficiency attenuates the fibrogenic response to ureteral obstruction. Kidney Int 2001;60: 587-596.

13 Ricardo SD, Ding G, Eufemio M, Diamond JR: Antioxidant expression in experimental hydronephrosis: role of mechanical stretch and growth factors. Am J Physiol 1997; 272:F789-F798.

14 Qi Z, Whitt I, Mehta A, et al: Serial determination of glomerular filtration rate in conscious mice using FITC-inulin clearance. Am J Physiol Renal Physiol 2004;286:F590F596.

15 Faulhaber-Walter R, Chen L, Oppermann $\mathrm{M}$, et al: Lack of $\mathrm{A} 1$ adenosine receptors augments diabetic hyperfiltration and glomerular injury. J Am Soc Nephrol 2008;19:722730.

16 Hashimoto S, Adams JW, Bernstein KE, Schnermann J: Micropuncture determination of nephron function in mice without tissue angiotensin-converting enzyme. Am J Physiol Renal Physiol 2005;288:F445-F452.

17 Tanimoto K, Sugiyama F, Goto Y, et al: Angiotensinogen-deficient mice with hypotension. J Biol Chem 1994;269:31334-31337.
18 Huby AC, Rastaldi MP, Caron K, Smithies O, Dussaule JC, Chatziantoniou C: Restoration of podocyte structure and improvement of chronic renal disease in transgenic mice overexpressing renin. PLoS One 2009;4: e6721.

19 Zhou XJ, Vaziri ND, Zhang J, Wang HW, Wang XQ: Association of renal injury with nitric oxide deficiency in aged SHR: prevention by hypertension control with AT1 blockade. Kidney Int 2002;62:914-921.

$>20$ Ruggenenti P: Angiotensin-converting enzyme inhibition and angiotensin II antagonism in nondiabetic chronic nephropathies. Semin Nephrol 2004;24:158-167.

-21 Guron G, Friberg P: An intact renin-angiotensin system is a prerequisite for normal renal development. J Hypertens 2000;18:123137.

22 Ouyang X, Le TH, Roncal C, et al: Th1 inflammatory response with altered expression of profibrotic and vasoactive mediators in AT1A and AT1B double-knockout mice. Am J Physiol Renal Physiol 2005;289:F902F910

-23 Yang B, Jain S, Ashra SY, Furness PN, Nicholson ML: Apoptosis and caspase-3 in longterm renal ischemia/reperfusion injury in rats and divergent effects of immunosuppressants. Transplantation 2006;81:14421450

24 Miyazaki Y Tsuchida S, Fogo A, Ichikawa I: The renal lesions that develop in neonatal mice during angiotensin inhibition mimic obstructive nephropathy. Kidney Int 1999; 55:1683-1695.

-25 Fitzgerald JP Chou SY, Franco I, Mooppan UM, Kim H, Saini R, Gulmi FA: Atorvastatin ameliorates tubulointerstitial fibrosis and protects renal function in chronic partial ureteral obstruction cases. J Urol 2009;182 (suppl):1860-1868 